\title{
ASSESSMENT OF TREE BIOMASS CARBON STOCK OF A SUBTROPICAL SCRUB FOREST, SOAN VALLEY PAKISTAN
}

\author{
GHAFOOR, G. Z. ${ }^{*}$ - SHARIF, F. - KHAN, A. U. - SHAHZAD, L. - HAYYAT, M. U. \\ Sustainable Development Study Center, Government College University Lahore, Pakistan \\ (email/phone:faizasharif@gcu.edu.pk/+92-321-4000-818; akeco1111@gmail.com/+92-300- \\ 8481-460; lailashahzad@gcu.edu.pk/+92-322-7878-517; umerenv@yahoo.com/+92-321- \\ 4032-300) \\ *Corresponding author \\ e-mail: zareen.sdsc@gmail.com; phone+92-343-4624-022 \\ (Received $7^{\text {th }}$ Oct 2019; accepted $4^{\text {th }}$ Dec 2019)
}

\begin{abstract}
In Pakistan the lack of development for local allometric equations has led to the use of simple generic volume equations which may generate errors in forest carbon estimates. This research was designed to quantify tree carbon stock and check the robustness of the existing models against local allometric models.The study was conducted in Hayat-ul-Mir subtropical scrub forest in Pakistan comprising of a bi-climax community of Acacia modesta Linn. and Olea ferruginea Royle.Tree measurements were taken in 47 plots of 0.04 ha and biomass carbon estimates were made using local allometric, existing generic pantropical model and i-Tree Eco tool.No significant difference in biomass carbon (ton/ha) was found between local (8.53) and pantropical models (8.68) for A. modesta and between the three models for $O$. ferruginea $(10.92,11.91$ and 11.87 for local allometric, pantropical model and i-Tree Eco, respectively). All models fitted data well $(p<0.001)$, whereas the pantropical model incorporating three biophysical variables better predicted biomass and was found more robust for both species based on AIC, BIC, RMSE and $\mathrm{R}^{2}$ adj. values. In the absence of local models, the pantropical model can provide better biomass estimates for deciduous and evergreen subtropical species to report carbon stock.
\end{abstract}

Keywords: Allometry, volume, i-Tree Eco, pantropical, REDD+

\section{Introduction}

Biomass carbon stock assessment is highly sensitive to the choice of adopted method due to differences in the biophysical factors incorporated into the model (van Breugel et al., 2011). Forest biomass carbon is partitioned mainly into aboveground (including stem, branches, and leaves) and belowground parts (including both fine and coarseroots) accounting for approximately 50\% of the total biomass of the tree (Basuki et al., 2009; Yuen et al., 2016). For biomass estimation, various techniques are common ranging from site specific or locally developed to generic allometric/regression models and remote sensing techniques (Basuki et al., 2009; van Breugel et al., 2011). The most accurate and direct method of biomass quantification employs the use of destructive or semidestructive sampling in which fresh and oven dry weight of all components or parts of a tree is analytically determined by harvesting subsample of plants from sample plots. The results obtained give a precise estimate of the biomass carbon in a small sample area, and this technique is being used to develop site or species specific (local) regression models for the landscape based biomass estimations (Basuki et al., 2009; Yuen et al., 2016). The destructive harvest is often limited due to variable topography, environmental and financial constraints (Goussanou et al., 2016; Djomo and Chimi, 2017). To overcome this limitation researchers have devised non-destructive volume and allometric equations to estimate individual tree biomass, for which biomass carbon as a fraction is calculated (Philip, 1994; Yuen et al., 2016; Stas et al., 2017). 
Allometry finds a mathematical explanation of how structural variables are related to biomass. This mathematical explanation or model is obtained by regressing total individual biomass of tree or its components against biophysical variables i.e. diameter at breast height (DBH), tree height and wood density (Chave et al., 2014; Yuen et al., 2016). Although generic allometric equations are considered applicable to wide range of species in diverse landscapes, but between the regions trees present different allometric relationships for biophysical variables depending on the environmental conditions such as climate and soil type. This requires the generic allometric models to be calibrated with local (site or species specific) allometries which gives a more precise estimate of tree carbon stock (Vieilledent et al., 2012). By this pre-calibration, the utility of generic models to wide range of environmental conditions and species increases when local biomass models are not available. Vieilledent et al. (2012) after a destructive sampling of 481 trees in Madagascar, developed local allometric equations and compared them with generic pantropical relations developed by Brown (1997) and Chave et al. (2005). The comparison showed that in the absence of local equations, the generic model proposed by Chave et al. (2005) based on height (Ht), DBH and wood density (WD) of tree species produced more accurate biomass estimates than other generic models considering only $\mathrm{DBH}$ or combination of $\mathrm{DBH}$ and WD.

The accuracy of the forest carbon estimates thus lies in the robustness of the allometric model adopted and also depends on the relationship between biophysical variables incorporated as predictors in the model (Gulzar et al., 2014). For instance, tree volume equations developed by foresters may relyon a geometric relationship of $\mathrm{Ht}, \mathrm{DBH}$ and tree form factor and applies biomass expansion factoror species specific WD to estimate tree biomass (Philip, 1994; Nizami, 2012). While the generic or pantropical models are developed considering the climate of the region along with biophysical factors and also apply regression coefficients in determining tree biomass (Chave et al., 2014). Biomass estimations made through any of these methods can later be extrapolated to the whole forest or landscape scale level (Nizami, 2014).

A number of tools have also been developed to estimate tree biomass and carbon storage in urban and natural forest such as Carbon OnLine Estimator (COLE), U.S. Forest Carbon Calculation Tool (CCT), Center for Urban Forestry Research (CUFR) Tree Carbon Calculator (CTCC) and i-Treetools (Aguaron and McPherson, 2012; Nowak et al., 2013; Russo et al., 2014). i-Tree Eco, developed by the USDA Forest Service and Cooperators, is derived from the UFORE (Urban FORest Effects) and has widely been used to estimate the magnitude and monetary value of many of the ecosystem services provided by urban forests, including carbon storage and sequestration using the plot based or complete inventory data of forest. The use of meteorological data by i-Tree Eco as a baseline gives a better estimate of ecosystem services (Nowak et al., 2008). i-Tree Eco computes dry weight biomass, carbon storage and sequestration by applying species/genus/family specific allometric equations or average of hardwood/conifer equations using either $\mathrm{DBH}$, a combination of $\mathrm{DBH}$ and $\mathrm{Ht}$ or $\mathrm{Ht}$ of the tree and crown characteristics (Nowak et al., 2013).

In order to implement REDD+ targets (Reducing Emissions from Deforestation and Forest Degradation) to reduce global greehouse gas emissions (Terakunpisut et al., 2007), it is mandatory for Pakistan to report its forest carbon stock and GHG emissions from other sectors in accordance with UNFCCC protocols. For this purpose, only a few allometric models have been developed in Pakistan for the estimation of biomass of individual tree components (stem, branches, twigs, leaves and root) or stem volume estimation (Nizami, 
2014; Shaheen et al., 2016). Whereas, most of the studies have reported biomass estimates using volume relationships (Nizami et al., 2009; Nizami, 2012; Ahmad et al., 2014; Shaheen et al., 2016) which are now less recommended due to its limitations of incorporating fixed tree form factor and limited utility for closed canopy forests (Chave et al., 2005). No literature was found to the best of our knowledge using i-Tree Eco tool or on validation of generic allometric models to estimate tree carbon stock in Pakistan.

This study was conducted on the Hayat-ul-Mir (HM) Scrub forest, Soan Valley Pakistan to estimate tree biomass carbon stock. The forest is documented in detail by Parker (1915) and Champion et al. (1965) as cited by Khan et al. (2013). The vegetation type of scrub forest comprises of dry subtropical broad leaved deciduous and evergreen species covering a totalarea of 1.3 million hectares. The forest extends in the foothills and lowerslope of Himalayas, in the salt range, Kala-Chitta, and Sulaiman range. At suitable elevations, the forest is also seen throughout the country merging upward with sub-tropical pine and temperate forest and downward with tropical thorn forest. The dominant community of the scrub forest comprise of Acacia modesta (Linn.) Wall., Olea ferruginea Royle, Tecoma undulata, and Pistacia integerima however shrub cover is contributed by Dodonea viscosa, Justica adhatoda, Zizyphus spp. And Nannorrhops ritchieana. The local population benefits from the forest to fulfill its needs for fodder, fuelwood, timber and herbal medicines (Khan and Ahmad, 2015).

A number of studies have been conducted in Pakistan estimating tree biomass of different forest ecosystems. Nizami et al. (2009) has reported biomass carbon stock of subtropical pine forest in Lehterar and Ghoragali forest subdivisions in Murree hills using simple volume relationship. In another study by Nizami (2012), volume based biomass carbon estimates have been reported for sub-tropical pine forest, Kherimurat scrub and Sohawa forests comprising of vegetation stock of Pinus roxburghii, Acacia modesta and Olea ferruginea. Shaheen et al. (2016) have reported volume based and species specific allometric relationships for forest carbon stocka ssessment in subtropical Himalayan forest in Kashmir comprising a mixed vegetation of Acacia spp., O. cuspidata, P. roxburghii, Punica gratum, Ficus spp., Broussonetia papyrifera, Melia azedarach, Mallotus philippensis and Delbergia sisso. Other studies have reported biomass estimates of Delbergia sisso and Picea smithiana by destructive harvest in Daphar irrigated plantation in Punjab province and Kumrat valley in Khyber Pakhtun Khawa Province in Pakistan, respectively (Ahmad et al., 2014; Gulzar et al., 2014). In all of these studies, tree biomass was estimated from generic volume equations which are now less recommended for carbon accounting (Chave et al., 2005).

Current study was designed to 1) estimate tree biomass and carbon storage of Acacia modesta and Olea ferruginea in HM scrub forest and 2) to compare locally developed allometric equations to the existing models to evaluate their robustness and applicability for subtropical forest in Pakistan. It was hypothesized that increase in the number of biophysical factors in biomass model gives a better estimate of forest carbon stock.

\section{Materials and Methods}

\section{Site description}

The study was conducted in HM Scrub Reserve forest $\left(32.54^{\circ} \mathrm{N}\right.$ and $\left.72.31^{\circ} \mathrm{E}\right)$ covering an area of 1646 ha in Soan Valley, district Khushab of Punjab province, Pakistan. Most of the hills in the valley have an average height between 400 to $1000 \mathrm{~m}$ and the highest point in the range i.e. Sakesar lies at a height of $1527 \mathrm{~m}$. The forest 
classified as arid receives annual precipitation of $600 \mathrm{~mm}$ which falls mostly during the monsoon (July to September), with an average annual temperature of $24^{\circ} \mathrm{C}$ (minimum temperature $1^{\circ} \mathrm{C}$ in January and an average maximum temperature of $36^{\circ} \mathrm{C}$ in June) making the area hot and dry with frequent droughts during summer and frost in winter (Ahmed, 2013; Khan et al., 2013). The forest has a dominant vegetation stock of two climax (mosaic) species i.e. A. modesta (deciduous) and O. ferruginea (evergreen), however a rich understory of other species such as Justicia adhatoda, Buxus sp., Dodonaea viscosa and other shrubs are present at different elevations in the forest (Ahmed, 2013). The invasion of exotic Prosopis juliflora species was also seen at some locations in the HM forest (Fig. Al).

\section{Field data collection}

For the non-destructive estimation of tree biomass carbon, 47 plots of $20 \mathrm{~m} \times 20 \mathrm{~m}$ (0.04 ha) were taken in the forest (Fig. 1, Table Al) during November 2017 to December 2018. To estimate the tree above ground biomass (AGB), tree dendrometric variables such as Diameter at Breast Height $(\mathrm{DBH})$ and the total height $(\mathrm{Ht})$ of the tree was measured following UNFCCC protocols. For multi stem trees (which forked below $1.3 \mathrm{~m}$ height), the individual diameter of each stem was recorded, summed the DBH squares and their square root was taken (Eq.l) producing a single value of DBH for a tree. Tree basal area was computed using equation below (Eq.2) (Nizami, 2012).

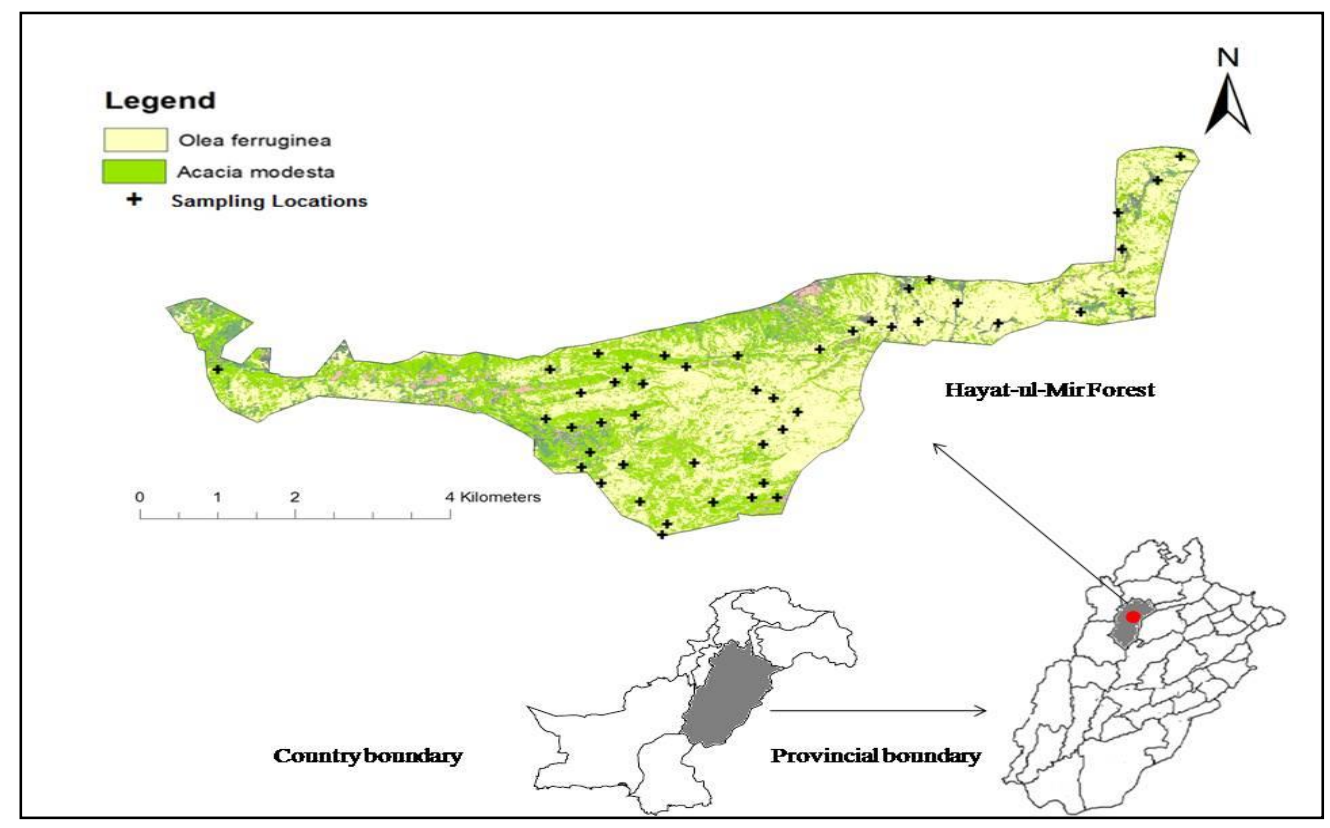

Figure 1.Spatial distribution of sampling plots taken in the HM forest

$$
\begin{aligned}
\mathrm{DBH}= & \operatorname{sqrt}\left[\mathrm{DBH}_{1}{ }^{2}+\mathrm{DBH}_{2}{ }^{2}+\ldots . \mathrm{DBH}_{\mathrm{n}}{ }^{2}\right] \\
& \text { Basal Area }=\pi / 4 \times \mathrm{DBH}^{2}
\end{aligned}
$$

The estimation of AGB of $A$. modesta and $O$. ferruginea in HM Reserve Forest was carried out using locally developed volume allometric equations which were considered 
as a benchmark to check the robustness of other two existing biomass estimation methods (non-destructive) for subtropical forest in cases when local equations are not available. This study is first of its kind to refine and caliberate existing generic biomass models against locally developed models for accurate carbon accounting under REDD+ in Pakistan and for other forests in subtropical region.

\section{AGB estimation using locally developed volume equations}

Local harvest based volume allometric equations (Pakistan Forest Institute, 1993) were used to estimate total volume of A. modesta (Eq.3) and O. ferruginea (Eq.4);

$$
\begin{gathered}
\ln \mathrm{TV}=-9.35092+0.36032 \ln \mathrm{H}+2.22653 \ln \mathrm{D} \\
\ln \mathrm{TV}=-9.3826+0.56528 \ln \mathrm{H}+2.09297 \ln \mathrm{D}
\end{gathered}
$$

Where TV is the total tree volume, $\ln$ is the natural logarithm, $\mathrm{H}$ is height and $\mathrm{D}$ is Diameter at Breast Height. These equations were used to compute individual tree volume of bi-climax community at HM forest which was later multiplied with species specific wood density (Philip, 1994; Nizami, 2012) adopted from World Agroforestry Database (Pearson and Brown 1932) to compute aboveground biomass (AGB).

\section{AGB estimation using generic pantropical biomass allometric equation}

The generic pantropical biomass allometric equation (Model 4 from Chave et al., 2014) was used to regress AGB of $A$. modesta and $O$. ferruginea against the product of height $(\mathrm{m}), \mathrm{DBH}(\mathrm{cm})$ and species specific wood density $\left(\mathrm{gcm}^{-3}\right)$. This model (based on harvest data from 58 sites across tropics with variable vegetation and climatic conditions) is a revised and improved version of Chave et al. (2005) and was selected as it performs well across forest types in pantropical bioclimatic conditions (Eq.5). The model is reported with slightly high variance and mean percent bias when compared with local models but no detectable effect of environmental factors or region on AGB considering height, DBH and wood density as covariates. The previous version (Chave et al., 2005) of this model has been evaluated by Kebede and Soromessa (2018) for $O$. europea L. sub sp. cuspidata (synonym O. ferruginea) in Ethiopia where allometric equations were developed through semi-destructive harvest and were compared with species specific and generic allometric models. This model has also been previously documented for O. europea by Tesfaye et al. (2016) and Muhati et al. (2018).

$$
\mathrm{AGB}_{\text {est }}(\mathrm{kg})=0.0673 \times\left(\rho \mathrm{D}^{2} \mathrm{H}\right)^{0.976}
$$

From the $\mathrm{AGB}_{\text {est }}$ obtained through local (Eqs.3 and 4) and generic allometric equations (Eq.5), belowground biomass (BGB) was calculated as $26 \%$ of the AGB (Nowak et al., 2008). The AGB and BGB were summed across individuals of both species and total tree biomass (TB) was converted into total tree biomass carbon (TBC) by multiplying with IPCC default factor of 0.50 as carbon accounts for $50 \%$ of the total biomass.

\section{Calculation of carbon storage through i-Tree Eco tool}

i-Tree Eco (v6.0) tool was used to estimate tree biomass and carbon stored in bi-climax community (A. modesta \& O. ferruginea) of HM forest. For this purpose, hourly annual 
metrological data and field measurements of $\mathrm{DBH}$, crown height, total tree height and crown light exposure (CLE) data was input into the tool to quantify total tree dry weight and carbon storage using species specific allometric equation. Crown light exposure was estimated considering number of sides of the crown exposed to sunlight following Bechtold (2003). The total tree (above and belowground) carbon in A. modesta and O. ferruginea was calculated using equation form 1 in the tool database (Eq.O).

$$
\text { Carbon Storage }=\exp ((\mathrm{A}+\mathrm{B} * \log (\text { Variable })+(\text { Mean Squared Error } / 2) / 2(\text { Eq.6) }
$$

where $\mathrm{A}$ and $\mathrm{B}$ are coefficients and Variable is $\mathrm{DBH}$ (A. modesta) or DBH \& Height $(O$. ferruginea). The total tree dry weight biomass (including $26 \%$ of the belowground biomass) was converted to carbon stock by multiplying with a factor of 0.5 (Nowak et al., 2013). This tool was selected for being a novel approach which has not yet been used for tree species in Pakistan and also it additionally quantifies other ecosystem services along with biomass estimates.

The plot based (0.04 ha) biomass estimates were up-scaled to hectare level using an appropriate area based conversion factor and both existing methods were evaluated against locally developed equations to choose the best fit model for carbon stock assessment of the subtropical forests in Pakistan.

\section{Data analysis}

For data analysis, SPSS v.19 (Statistical Package for Social Sciences) was used. Independent sample $t$-test was performed to evaluate statistical relationship between biophysical factors (dendrometric factors) of the surveyed population of both species. Mean and standard errors of biomass and carbon estimates were computed to compare for the variation in estimates made by each method. Multiple comparisons were made using Repeated Measures ANOVA and Bonferroni statistics was used to find the significant differences in carbon storage estimates made by each method used in this study. Multiple linear and logistic regression analyses were also run to choose the best fit model based on their relative performance considering $\mathrm{TB}$ as dependent and biophysical factors (DBH, Ht, \& WD) as independent variables (Eq.7).

$$
\mathrm{Y}=\mathrm{a}+\mathrm{b}_{1} \mathrm{X}_{1}+\mathrm{b}_{2} \mathrm{X}_{2}+\ldots . . \mathrm{b}_{\mathrm{n}} \mathrm{X}_{\mathrm{n}}
$$

In the equation above $\mathrm{Y}$ refers to the dependent variable, $\mathrm{a}$ is the $\mathrm{Y}$-intercept, $\mathrm{b}_{1}$ through $b_{n}$ corresponds to regression coefficients and $X$ represents independent variable(s). Goodness of fit statistics was considered for a model which had high value of $\mathrm{R}^{2}$-adj., lowest AIC (Aikaike Information criteria), BIC (Beysian Information Criteria), RMSE (Root Mean Square Error) and $p$ value $\leq 0.05$. AIC and BIC were estimated by equations below (Eq.8 and Eq.9) where $k=$ number of estimated parameters in the model and $L=$ maximized likelihood function of the estimated model.

$$
\begin{gathered}
\mathrm{AIC}=2 k-2 \ln (L) \\
\mathrm{BIC}=\ln (n) k-2 \ln (L)
\end{gathered}
$$




\section{Results}

\section{Structural summary of the forest}

In the HM forest, a total population of 399 trees (135 trees of A. modesta and 264 trees of $O$. ferruginea) was recorded in 47 survey plots $(0.04$ ha). Forest dendrometric characteristics have been presented in Table 1. O. ferruginea had higher tree density per hectare (150 trees/ha) than $A$. modesta ( 82 trees/ha). There was a significant difference in tree height $(t=3.76, d f=397, p<0.001)$, DBH $(t=3.11, d f=397, p<0.01)$ and basal area $(t=3.14, d f=397, p<0.05)$ of both species but not in case of tree volume $(t$ $=-0.251, d f=83, p=0.802)$ with highest mean DBH $(20.69 \pm 0.8 \mathrm{~cm})$ and height $(5.94$ $\pm 0.1 \mathrm{~m})$ recorded for $A$. modesta and basal area $\left(4.46 \pm 0.6 \mathrm{~m}^{2} / \mathrm{ha}\right)$ and tree volume $\left(17.10 \pm 2.4 \mathrm{~m}^{3} / \mathrm{ha}\right)$ recorded for $O$. ferruginea in the survey plots.

Table 1. Dendrometric characteristics of the Hayat-ul-Mir Forest

\begin{tabular}{c|c|c|c|c|c}
\hline \multirow{2}{*}{ Species } & \multirow{2}{*}{ Trees/ha } & $\begin{array}{c}\text { Height } \\
(\mathbf{m})\end{array}$ & $\begin{array}{c}\text { DBH } \\
(\mathbf{c m})\end{array}$ & $\begin{array}{c}\text { Basal area } \\
\left(\mathbf{m}^{2} / \mathbf{h a}\right)\end{array}$ & $\begin{array}{c}\text { Tree volume } \\
\left(\mathbf{m}^{\mathbf{3}} / \mathbf{h a}\right)\end{array}$ \\
\cline { 2 - 6 } & & $\boldsymbol{M} \pm \boldsymbol{S E}$ & $\boldsymbol{M} \pm \boldsymbol{S E}$ & $\boldsymbol{M} \pm \boldsymbol{S E}$ & $\boldsymbol{M} \pm \boldsymbol{S E}$ \\
\hline A. modesta & 82 & $5.94 \pm 0.1 * * *$ & $20.69 \pm 0.8^{* *}$ & $3.44 \pm 0.4$ & $16.22 \pm 2.6$ \\
O.ferruginea & 150 & $5.15 \pm 0.1$ & $17.78 \pm 0.4$ & $4.46 \pm 0.6^{*}$ & $17.10 \pm 2.4$ \\
\hline \multirow{2}{*}{$* * \mathrm{p}<0.001, * * \mathrm{p}<0.01, * \mathrm{p}<0.05$}
\end{tabular}

\section{Tree biomass and carbon storage}

Both methods of biomass estimation used in this study produced comparable estimates for both species when evaluated against locally developed equations. On plot scale the TB and TBC of sampled population presented in Table 2 shows that the generic allometric equation of Chave et al. (2014) produced slightly higher (70.88 ton and 35.44 ton) while i-Tree Ecotool produced lower (58.77 ton and 29.38 ton) TB and TBC estimates compared to the species specific local equations for bi-climax community (67.12 ton and 33.56 ton).

Table 2. Total tree biomass and carbon storage in survey plots

\begin{tabular}{c|c|c|c|c|c|c}
\hline \multirow{2}{*}{ Species } & \multicolumn{3}{|c|}{ Tree biomass (ton) } & \multicolumn{3}{c}{ Tree biomass carbon (ton) } \\
\cline { 2 - 7 } & Local Eq. & Chave et al. (2014) & i-TreeEco & Local Eq. & $\begin{array}{c}\text { Chave et al. } \\
\text { (2014) }\end{array}$ & i-Tree Eco \\
\hline A. modesta & 28.66 & 28.96 & 16.97 & 14.33 & 14.48 & 8.48 \\
O.ferruginea & 38.45 & 41.92 & 41.80 & 19.22 & 20.96 & 20.90 \\
\hline Total & 67.12 & 70.88 & 58.77 & 33.56 & 35.44 & 29.38 \\
\hline
\end{tabular}

Figure 2 illustrates the mean of TB and TBC of both species of scrub forest estimated using the selected methods. It can be seen from figure below that i-Tree Eco produced lower TB and TBC estimates (10.34 ton/ha and 5.17 ton/ha) than generic pantropical allometric equation (17.36 ton/ha and 8.68 ton/ha) and local (17.06 ton/ha and 8.53 ton/ha) allometric equations when evaluated for $A$. modesta. However, in case of $O$. ferruginea both existing methods produced comparable but slightly higher estimates than local equation.

Repeated measures ANOVA with Greenhouse-Geisser correction showed that mean TB and TBC significantly differed between the methods for $A$. modesta $(F(1.536,205.78)=$ 
31.22, $p=0.000)$ but not for $O$. ferruginea $(F(1.429,375.78)=2.162, p=0.132)$. For $A$. modesta, Post hoc test using Bonferroni correction revealed that the TB and TBC estimates of generic pantropical allometric equation of Chave et al. (2014) were not significantly different from the estimates of local equation $(p=1.000)$ but differed significantly in case of i-Tree Eco $(p=0.000)$ as shown in Figure 2.
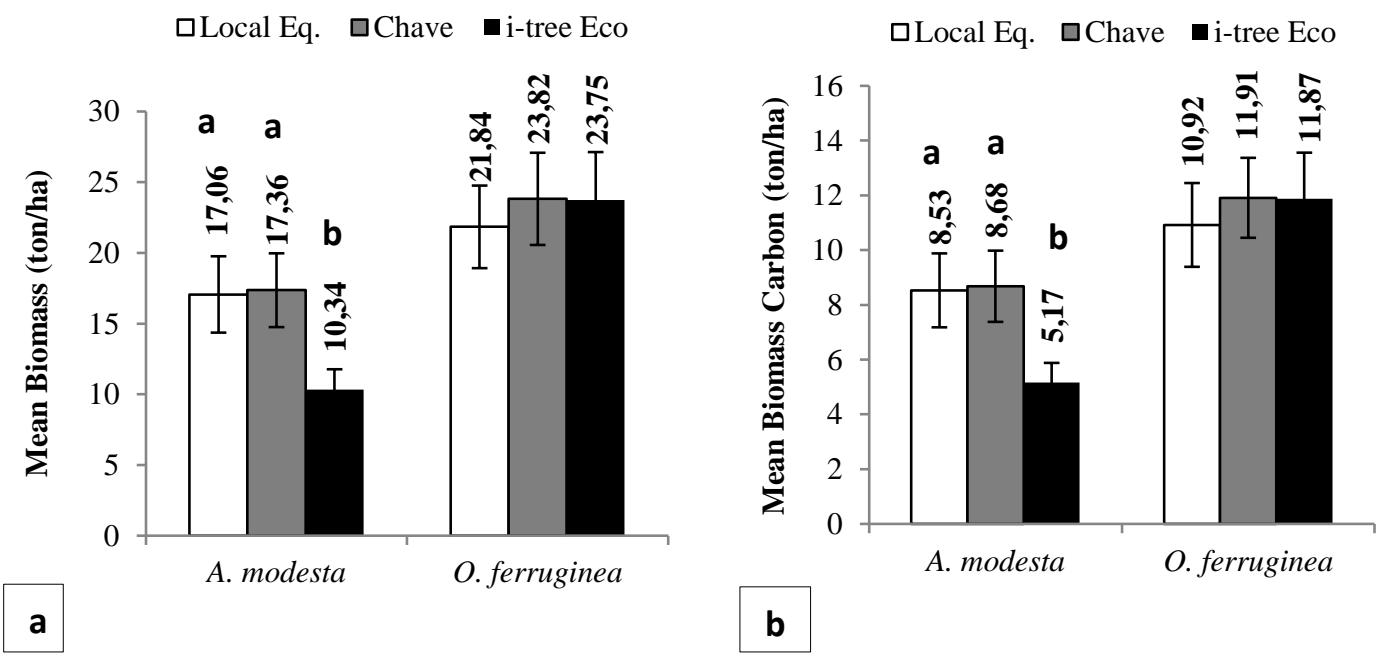

Figure 2. Mean of (a) total biomass (TB) and (b) total biomass carbon (TBC) calculated using three different methods (bars with similar letters are not significantly different at $p \geq 0.05$ )

\section{Model assessment}

The results of multiple linear regression analysis (Table 3) showed that the covariate DBH was statistically significant $(p<0.001)$ in all models for both species but height was not statistically significant in the local equations and i-Tree Eco (for $O$. ferruginea only). In case of both species, all of the models were good fit at $p<0.001$ but highest $\mathrm{R}^{2}$-adj. (0.802), lowest AIC, BIC and RMSE were reported by generic pantropical allometric model of Chave et al. (2014) for A. modesta. However, for O. ferruginea the highest $\mathrm{R}^{2}$-adj. (0.809) and lowest RMSE (0.093) were reported by local equation and lowest AIC and BIC by Chave et al. (2014).

Table 3. Goodness of fit statistics of regression models for the prediction of TB across both species in the HM forest

\begin{tabular}{c|c|c|c|c|c}
\hline \multirow{2}{*}{ Models } & \multicolumn{3}{|c|}{ Selection Criteria } & \multirow{2}{*}{ Biophysical variables } \\
\cline { 2 - 5 } & AIC & BIC & $\mathbf{R}^{\mathbf{2}}$ adj. & RMSE & \\
\hline Acacia modesta & & & & & \\
Local Equation & 1402 & 2455 & $0.792^{* * *}$ & 0.186 & $\mathrm{DBH}^{* * *}, \mathrm{H}$ \\
Chave et al. (2014) & 1379 & 2399 & $0.802^{* * *}$ & 0.138 & $\mathrm{DBH}^{* * *}, \mathrm{H}^{*}$ \\
i-Tree Eco tool & 2060 & 2803 & $0.738^{* * *}$ & 0.193 & $\mathrm{DBH}^{* * *}$ \\
Olea ferruginea & & & & & \\
Local Equation & 4179 & 8013 & $0.809^{* * *}$ & 0.093 & $\mathrm{DBH}^{* * *}, \mathrm{H}$ \\
\hline Chave et al. (2014) & 4057 & 7809 & $0.802^{* * *}$ & 0.104 & $\mathrm{DBH}^{* * *}, \mathrm{H}^{* * *}$ \\
i-Tree Eco tool & 4253 & 8174 & $0.752^{* * *}$ & 0.137 & $\mathrm{DBH}^{* * *}, \mathrm{H}$ \\
\hline
\end{tabular}

$* * * p<0.001, * p<0.05$, AIC = Akaike Information Criteria, BIC = Beysian Information Criteria, $\mathrm{RMSE}=$ Root Mean Square Error 


\section{Discussion}

This study provides a comparison of methods that can be used to predict the biomass carbon stock of subtropical forests in Pakistan. In this study both existing models compared against the locally developed equations showed goodness of fit statistics at $p<0.001$. The individual significance of biophysical variables (DBH \& $\mathrm{Ht}$ ) in predicting TB was also assessed through regression analysis. In case of both species, the generic allometric model of Chave et al. (2014) was found better predicting TB considering both $\mathrm{DBH}$ and Ht. There was an insignificant relationship of height with TB showing that $\mathrm{i}$-Tree Eco was predicting TB using DBH only suggesting utility of this tool to predict TB if height data is not available for these two species. i-Tree Eco provides a range of dataset of species specific allometric equations for many other species across diverse climatic range. The locally developed allometric equation for $A$. modesta and $O$. ferruginea also showed similar relation with DBH $(p<0.001)$ and tree height ( $p=0.793$ and $p=0.104$, respectively) suggesting the relative importance of inclusion of individual biophysical variables in the local model.

Goodness of fit statistics of the models used in this study was evaluated on the basis of multiple criteria. Any model which had high value of $\mathrm{R}^{2}$ adj., lowest AIC, BIC and RMSE was considered best model in predicting TB of bi-climax community of the HM forest. In case of this study, when compared to the locally developed allometric equations, the lowest AIC and BIC was found for the generic pantropical allometric model of Chave et al. (2014) for both species. This model also reported high value of $\mathrm{R}^{2}$ adj. When evaluated for $A$. modesta but only slightly less than local equation for $O$. ferruginea. This generic model has originally been developed by taking harvest dataset of multiple species across the tropical region (Chave et al., 2014) and its evaluation in this study confirms its robustness and reliability for the forest carbon stock assessment in the subtropical region of Pakistan as well. Results of this study are consistent to the findings of Kebede and Soromessa (2018), reporting goodness of fit statistics of four species specific allometric equations for $O$. europea sub sp. cuspidata (synonym of $O$. ferruginea) at $p<0.001$ and found a strong correlation of AGB with DBH and height but insignificant relation with wood density. Similarly these results are also consistent to the findings of Vieiledent et al. (2012) who reported generic models of Chave et al. (2005) as more reliable and producing less bias for TBC estimates of tropical forests when compared with other generic models.

Among the biomass and carbon estimates, the post hoc test showed no significant difference between the estimates made with local equation and generic allometric equation of Chave et al. (2014) when compared for A. modesta, but i-Tree Eco significantly underestimated the TB and TBC. Reasons for this underestimation might be because i-Tree Eco considered DBH only for A. modesta in its equation form 1 and also it computes the weight of wood only in TBC estimates for the deciduous tree species (Nowak et al., 2008). i-Tree Eco relying on DBH only did not perform well with low $\mathrm{R}^{2}$ adj. and high RMSE and AIC compared to the local and pantropical models. Similar results have been reported by Ruiz-Peinado et al. (2012), Huy et al. (2016) and Djomo and Chimi (2017) stating that inclusion of two (DBH \& Ht) or three covariates (DBH, Ht \& WD) in allometric models better predict biomass than models with DBH only as covariate. From this analysis it can be inferred that in the absence of local allometric equations or restriction in doing destructive harvest to accurately measure the TBC, the pantropical model of Chave et al. (2014) can be used as an alternative to better 
predict the TBC relying on the field measurements of DBH, height and wood density in subtropical forest.

In case of $O$. ferruginea, the post hoc test showed no significant difference in the means of TBC estimated with local equation and other two existing models. The analysis suggests that both existing models accurately estimated TBC for subtropical scrub forest compared to the local model and can be considered as equal candidate models in predicting TBC if the local equations are not available. In such case it could be advantageous to select the pantropical equation of Chave et al. (2014) than i-Tree Eco considering their relative values of $\mathrm{AIC}, \mathrm{BIC}$ and $\mathrm{R}^{2}$ adj.

Most of the biomass estimates in Pakistan are made using generic volume equation of Philip (1994) which draws simple geometric relationship between the basal area (Eq. $2)$, height $(\mathrm{H})$ and form factor $(\mathrm{F})$ multiplied with species specific wood density $(\rho)$ of tree $(\mathrm{AGB}=\rho \times[\mathrm{BA} \times \mathrm{F} \times \mathrm{H})$. This model was developed by foresters and is now seldom used in carbon accounting as it assumes fixed form factor and also cannot predict biomass if height data is not available in close canopy forests (Chave et al., 2005). A comparison of biomass estimates of this study has been made with other studies conducted on sub-tropical forests in Pakistan (Table 4). The TB estimates of $A$. modesta made using local allometric equation in this study are comparable to the findings of Nizami (2010, 2012) made through Philip (1994) in Kherimurat and Sohawa scrub forests in Pakistan. The species specific allometric equation used by Shaheen et al. (2016) underestimated the TB of $A$. modesta $(12.7 \mathrm{t} / \mathrm{ha}$ ) in the mixed forest at two sites in the Muzaffarabad District, Pakistan compared to the findings of this study. In case of $O$. ferruginea the TB was overestimated (approx. Four times) with volume equation (Philip, 1994) in Shaheen et al. (2016) than current study. The difference in the estimates might be due to the incorporation of differentset of biophysical variables in species specific, generic allometric and simple volume equations in both studies. Other reasons for the difference in the estimates might be related to the tree density, topographic and climatic differences as the subtropical forest in Muzaffarabad district is at a higher elevation, has low temperature and receives higher rainfall than the HM forest as summarized in Table 4. Located at the foothills of lesser Himalaya the subtropical forest in Muzaffarabad district is also under anthropogenic threats (not a protected forest) and the local population rely heavily on forest for its needs related to timber, food, fodder and fuelwood resulting in under reporting of actual tree biomass and carbon (Shaheen et al., 2016).

i-TreeEco has widely been used for the estimation of carbon storage and sequestration in urban forests across the United States and European countries. To the best of our knowledge none of the study citing i-Tree Eco for reporting carbon storage of tree species from Pakistan was found in the literature. The tool calculates carbon storage and sequestration using allometric equations based on natural forest-grown North American tree species and socan fairly be used for both natural and urban forests (Nowak et al., 2013; Russo et al., 2014). Results of this study (for A. modesta) are consistent to the findings of Russo et al. (2014) who compared the allometric equation against i-Tree Eco and CUFR Tree Carbon Calculator (CTCC) and reported the highest carbon storage value with the allometric equation (179.14 ton), followed by CTCC (140.15 ton) and lowest by i-Tree Eco (134.89 ton) in Bolzano's urban forest, Italy. Results of present study for $O$. ferruginea are contrary to the Aguaron and McPherson (2012) who compared four sets of allometric equations i.e. i-Tree Eco, i-Tree Street, CTCC and Urban General Equations and calculated $\mathrm{CO}_{2}$ storage of Sacramento's urban forest. 
Table 4. Comparison of biomass estimates of HM forest and other subtropical forests in Pakistan

\begin{tabular}{|c|c|c|c|c|c|c|c|c|c|c|c|c|c|}
\hline \multirow{3}{*}{$\begin{array}{c}\text { Reference (Forest } \\
\text { type) }\end{array}$} & \multirow{3}{*}{ Study site } & \multirow{3}{*}{$\begin{array}{l}\text { Elevation } \\
\text { (m) }\end{array}$} & \multirow{3}{*}{ Legal status } & \multicolumn{2}{|c|}{ Climate } & \multicolumn{4}{|c|}{ Acaciamodesta } & \multicolumn{4}{|c|}{ Oleaferruginea } \\
\hline & & & & \multirow[b]{2}{*}{ Temp. $\left({ }^{\circ} \mathrm{C}\right)$} & \multirow{2}{*}{$\begin{array}{c}\text { Av. } \\
\text { Rainfall } \\
(\mathrm{mm} / \mathrm{yr})\end{array}$} & \multirow[b]{2}{*}{ Trees/ha } & \multicolumn{3}{|c|}{ TB estimation method (t/ha) } & \multirow[b]{2}{*}{ Trees/ha } & \multicolumn{3}{|c|}{ TB estimationmethod (t/ha) } \\
\hline & & & & & & & $\begin{array}{c}\text { Volume } \\
\text { eq. }\end{array}$ & $\begin{array}{c}\text { Allometric } \\
\text { eq. }\end{array}$ & $\begin{array}{c}\text { i-Tree } \\
\text { Eco }\end{array}$ & & $\begin{array}{l}\text { Volume } \\
\text { eq. }\end{array}$ & $\begin{array}{c}\text { Allometric } \\
\text { eq. }\end{array}$ & i-Tree Eco \\
\hline $\begin{array}{c}\text { Current study } \\
\text { (Subtropical scrub) }\end{array}$ & Hayat-ul-Mir & $457-1067$ & Reserved forest & 24 (Av.) & 800 & 74 & 17 & 17.4 & 10.3 & 152 & 21.8 & 23.8 & 23.8 \\
\hline $\begin{array}{c}\text { Nizami } \\
(\mathbf{2 0 1 0 , 2 0 1 2 )} \\
\text { (Subtropical scrub) }\end{array}$ & $\begin{array}{c}\text { Kherimurat } \\
\text { Sohawa }\end{array}$ & 348 & $\begin{array}{l}\text { Protected forest } \\
\text { Protected forest }\end{array}$ & $\begin{array}{l}38 \text { (Max) } \\
15 \text { (Min) }\end{array}$ & $750-780$ & $\begin{array}{l}197 \\
179 \\
\end{array}$ & $\begin{array}{l}15 \\
15 \\
\end{array}$ & & & $\begin{array}{l}94 \\
56 \\
\end{array}$ & $\begin{array}{l}35.7 \\
25.3\end{array}$ & & \\
\hline $\begin{array}{c}\text { Shaheen et al. (2016) } \\
\text { (Subtropical scrub) }\end{array}$ & $\begin{array}{c}\text { Muzaffarabad } \\
\text { District }\end{array}$ & $800-1300$ & NA & 20 (Av.) & 1511 & NA & & 12.7 & & 620 & 68.9 & & \\
\hline
\end{tabular}

NA = Not available 
The study reported highest estimates by i-Tree Streets $(6.41 \mathrm{Mt})$ and CTCC (6.4 Mt) followed by urban general equations $(5.1 \mathrm{Mt})$ and lowest estimates by i-Tree Eco (4.9 $\mathrm{Mt}$ ). In both above mentioned studies i-Tree Eco produced the lowest estimates than other methods because in both studies AGB estimates were reduced by applying a correction factor of 0.80 before computing total tree dry weight. i-Tree Eco is designed on the basis of forest grown trees so this correction factor is applied to the open grown trees as they produce less aboveground biomass than forest grown trees (Aguaron and McPherson, 2012; Nowak et al., 2013; Russo et al., 2014). The latest version of i-Tree Eco however considers crown light exposure (CLE) in place of landuse and applies this correction factor to trees with 4 or 5 CLE. This might be one reason for differences in the estimates of HM carbon stock and other studies.

All of the methods used in this study have produced comparable results with relatively minor mean differences which might have arisen from the variation in the input of tree biophysical factors and/or values of coefficients used in allometric equations evaluated in this study. Findings of Huy et al. (2016) also reported dissimilar values of coefficients of allometric equations as one reason for the variation in AGB estimates of broadleaf evergreen forests in Vietnam.

\section{Conclusion}

Reporting and implementation of REDD+ targets in Pakistan requires accurate assessment of forest biomass carbon through reliable methods. This study conducted in the HM forest reported high tree density and biomass of $O$. ferruginea but at lower $\mathrm{DBH}$ and height than A. modesta. The study provides first evidence of applicability of existing generic biomass allometric models in the subtropical forest in Pakistan. All of the models used in this study fitted data well but among them the models considering both height and DBH as covariates better predicted total biomass than other (DBH only) based on $\mathrm{R}^{2}$ adj., RMSE, AIC and BIC values. For $O$. ferruginea both existing models accurately predicted TB when compared to the local equation while in case of $A$. modesta significant underestimation of TB was reported by i-Tree Eco (DBH only model for this species). Considering the multiple criteria (AIC, BIC, $\mathrm{R}^{2}$ adj. and RMSE) to evaluate the good fit statistics of the existing models against the local equations, the generic pantropical model of Chave et al. (2014) was found better predicting TB suggesting its wide applicability and robustness for both deciduous and evergreen species while i-Tree Eco for evergreen species only in subtropical forests in the absence of local allometric equations. The analysis done in this study is helpful in selecting an appropriate biomass model for subtropical region to report carbon stock changes under REDD+. The study suggests that local and generic subtropical models considering the additional effect of other factors like crown area, site characteristics and forest type must be developed and caliberated for more precise accounting of national carbon stock.

Acknowledgements. Authors are thankful to the Higher Education Commission of Pakistan for providing funds (Project No. 3867) to conduct this research and to the officials from Forest Department of Naushehra, District Khushab Pakistan for helping in the field survey. 


\section{REFERENCES}

[1] Aguaron, E., McPherson, E.G. (2012): Comparison of methods for estimating carbon dioxide storage by Sacramento's urban forest. - Carbon Sequestration in Urban Ecosystems: 43-71. Springer, Dordrecht. 10.1007/978-94-007-2366-5_3.

[2] Ahmad, S., Ahmad, A., Nizami, S.M. (2014): Assessment of biomass expansion factor of Piceasmithiana (Wall) Boiss. - International Journal of Scientific and Engineering Research 5: 1232-1239.

[3] Ahmed, F. (2013): Vegetation Description of three Scrub Forests of Salt Range. - FUUAST Journal of Biology 3: 157.

[4] Basuki, T.M., Van Laake, P.E., Skidmore, A.K., Hussin, Y.A. (2009): Allometric equations for estimating the above-ground biomass in tropical lowland Dipterocarp forests. - Forest Ecology and Management 257: 1684-1694. 10.1016/j.foreco.2009.01.027.

[5] Bechtold, W. A. (2003): Crown position and light exposure classification - An alternative to field-assigned crown class. - Northern Journal of Applied Forestry 20(4): 154-160.

[6] Brown, S. (1997): Estimating biomass and biomass change of tropical forests: A primer. - FAO Forestry Paper 134.

[7] Champion, H.G., Seth, S.K., Khattak, G.M. (1965): Forest Types of Pakistan. - Pakistan Forest Institute, Peshawar.

[8] Chave, J., Andalo, C., Brown, S., Cairns, M.A., Chambers, J.Q., Eamus, D., Folster, H., Fromard, F., Higuchi, N., Kira, T., Lescure, J.P. (2005): Tree allometry and improved estimation of carbon stocks and balance in tropical forests. - Oecologia 145: 87-99. 10.1007/s00442-005-0100-x.

[9] Chave, J., Réjou-Méchain, M., Búrquez, A., Chidumayo, E., Colgan, M.S., Delitti, W.B., Duque, A., Eid, T., Fearnside, P.M., Goodman, R.C., Henry, M. (2014): Improved allometric models to estimate the aboveground biomass of tropical trees. - Global Change Biology 20: 3177-3190. 10.1111/gcb.12629.

[10] Djomo, A.N., Chimi, C.D. (2017): Tree allometric equations for estimation of above, below and total biomass in a tropical moist forest: Case study with application to remote sensing. - Forest Ecology and Management 391: 184-193.

[11] Goussanou, C.A., Guendehou, S., Assogbadjo, A.E., Kaire, M., Sinsin, B., Cuni-Sanchez, A.(2016): Specific and generic stem biomass and volume models of tree species in a West African tropical semi-deciduous forest. - Silva Fennica 50(2):1474. http://dx.doi. org/10.14214/sf.1474.

[12] Gulzar, S., Nizami, S.M., Saleem, A., Mirza, S.N., Mahmood, T. (2014): Allometric relationships for predicting the biomass in Dalbergia sissoo roxb. plantation in Punjab, Pakistan. - Pakistan Journal of Agriculture Science 51: 525-529.

[13] Huy, B., Poudel, K.P., Temesgen, H. (2016): Aboveground biomass equations for evergreen broadleaf forests in South Central Coastal ecoregion of Viet Nam: Selection of eco-regional or pantropical models. - Forest Ecology and Management 376: 276-283. 10.1016/j.foreco.2016.06.031.

[14] Kebede, B., Soromessa, T. (2018): Allometric equations for aboveground biomass estimation of Olea europaea L. subsp. cuspidata in Mana Angetu Forest. - Ecosystem Health and Sustainability 4(1): 1-12. 10.1080/20964129.2018.1433951.

[15] Khan, A.U., Ahmad, F., Sharif, F. (2013): Rapid ranking method for prioritizing restoration by evaluating human influences on the status of scrub forest: A case study. - Pakistan Journal of Botany 45(1): 11-16.

[16] Khan, A.U., Ahmad, F. (2015): Establishing links between wood trading, grazing and mining activities with the underlying trends of continuous decline of natural scrub forest cover in the Soan Valley. - FUUAST Journal of Biology 5(1): 55-62.

[17] Muhati, G.L., Olago, D., Olaka, L. (2018): Quantification of carbon stocks in Mount Marsabit Forest Reserve, a sub-humid montane forest in northern Kenya under anthropogenic disturbance. - Global Ecology and Conservation 14: e00383. 10.1016/j.gecco.2018.e00383. 
[18] Nizami, S.M., Mirza, S.N., Livesley, S., Arndt, S., Fox, J.C., Khan, I.A., Mahmood, T. (2009): Estimating carbon stocks in sub-tropical pine (Pinus roxburghii) forests of Pakistan. - Pakistan Journal of Agriculture Science 46: 266-270.

[19] Nizami, S.M. (2010): Estimation of carbon stocks in subtropical managed and unmanaged forests of Pakistan. - Ph. D thesis. Arid Agriculture University, Rawalpindi, Pakistan.

[20] Nizami, S.M. (2012): The inventory of the carbon stocks in sub tropical forests of Pakistan for reporting under Kyoto Protocol. - Journal of Forestry Research 23: 377-384. 10.1007/s11676012-0273-1.

[21] Nizami, S. M. (2014): Status of tree volume calculation and development of allometric equations in Pakistan. - International Journal of Scientific \& Engineering Research 5: 441-446.

[22] Nowak, D.J., Crane, D.E., Stevens, J.C., Hoehn, R.E., Walton, J.T., Bond, J. (2008): A groundbased method of assessing urban forest structure and ecosystem services. - Aboriculture \& Urban Forestry 34: 347-358.

[23] Nowak, D.J., Greenfield, E.J., Hoehn, R.E., Lapoint, E. (2013): Carbon storage and sequestration by trees in urban and community areas of the United States. - Environmental Pollution 178: 229-236. 10.1016/j.envpol.2013.03.019.

[24] Pakistan Forest Institute. (1993): Revised volume tables of tree species growing on the farmlands in NWFP. - Forestry Research Division. Forest Mensuration Branch, Pakistan Forest Institute.

[25] Parker, R.N. (1915): A Forest Flora for the Punjab with Hazara and Delhi. - Lahore Government Printing Press West Pakistan.

[26] Pearson, R.S., Brown, H.P. (1932): Commercial timbers of India.Their distribution, supplies, anatomical structure, physical and mechanical properties and uses. - Nature 132: 727-728.

[27] Philip, M.S. (1994): Measuring trees and forests. $-2^{\text {nd }}$ ed. Wallingford: CAB international.

[28] Ruiz-Peinado, R., Montero, G., del Rio, M. (2012): Biomass models to estimate carbon stocks for hardwood tree species. - Forest Systems 21(1): 42-52.

[29] Russo, A., Escobedo, F.J., Timilsina, N., Schmitt, A.O., Varela, S., Zerbe, S. (2014): Assessing urban tree carbon storage and sequestration in Bolzano, Italy. - International Journal of Biodiversity Science and Ecosystem Service Management 10: 54-70. 10.1080/21513732.2013.873822.

[30] Shaheen, H., Khan, R.W.A., Hussain, K., Ullah, T.S., Nasir, M., Mehmood, A. (2016): Carbon stocks assessment in subtropical forest types of Kashmir Himalayas. - Pakistan Journal Botany 48: 2351-2357.

[31] Stas, S.M., Rutishauser, E., Chave, J., Anten, N.P., Laumonier, Y. (2017): Estimating the aboveground biomass in an old secondary forest on limestone in the Moluccas, Indonesia: Comparing locally developed versus existing allometric models. - Forest Ecology Management 389: 27-34. 10.1016/j.foreco.2016.12.010.

[32] Terakunpisut, J., Gajaseni, N., Ruankawe, N. (2007): Carbon sequestration potential in aboveground biomass of Thong PhaPhum national forest, Thailand. - Applied Ecology And Environmental Research 5(2): 93-102.

[33] Tesfaye, M.A., Bravo-Oviedo, A., Bravo, F., Ruiz-Peinado, R. (2016): Aboveground biomass equations for sustainable production of fuelwood in a native dry tropical afro-montane forest of Ethiopia. - Annals of Forest Science 73(2): 411-423. 10.1007/s13595-015-0533-2.

[34] van Breugel, M., Ransijn, J., Craven, D., Bongers, F., Hall, J.S. (2011): Estimating carbon stock in secondary forests: decisions and uncertainties associated with allometric biomass models. Forest Ecology and Management 262: 1648-1657.

[35] Vieilledent, G., Vaudry, R., Andriamanohisoa, S.F., Rakotonarivo, O.S., Randrianasolo, H.Z., Razafindrabe, H.N., Rakotoarivony, B., Rasamoelina, M. (2012): A universal approach to estimate biomass and carbon stock in tropical forests using generic allometric models. Ecological Applications 22: 572-583.

[36] Yuen, J.Q., Fung, T., Ziegler, A.D. (2016): Review of allometric equations for major land covers in SE Asia: uncertainty and implications for above-and below-ground carbon estimates. - Forest Ecology and Management 360: 323-340. 10.1016/j.foreco.2015.09.016. 


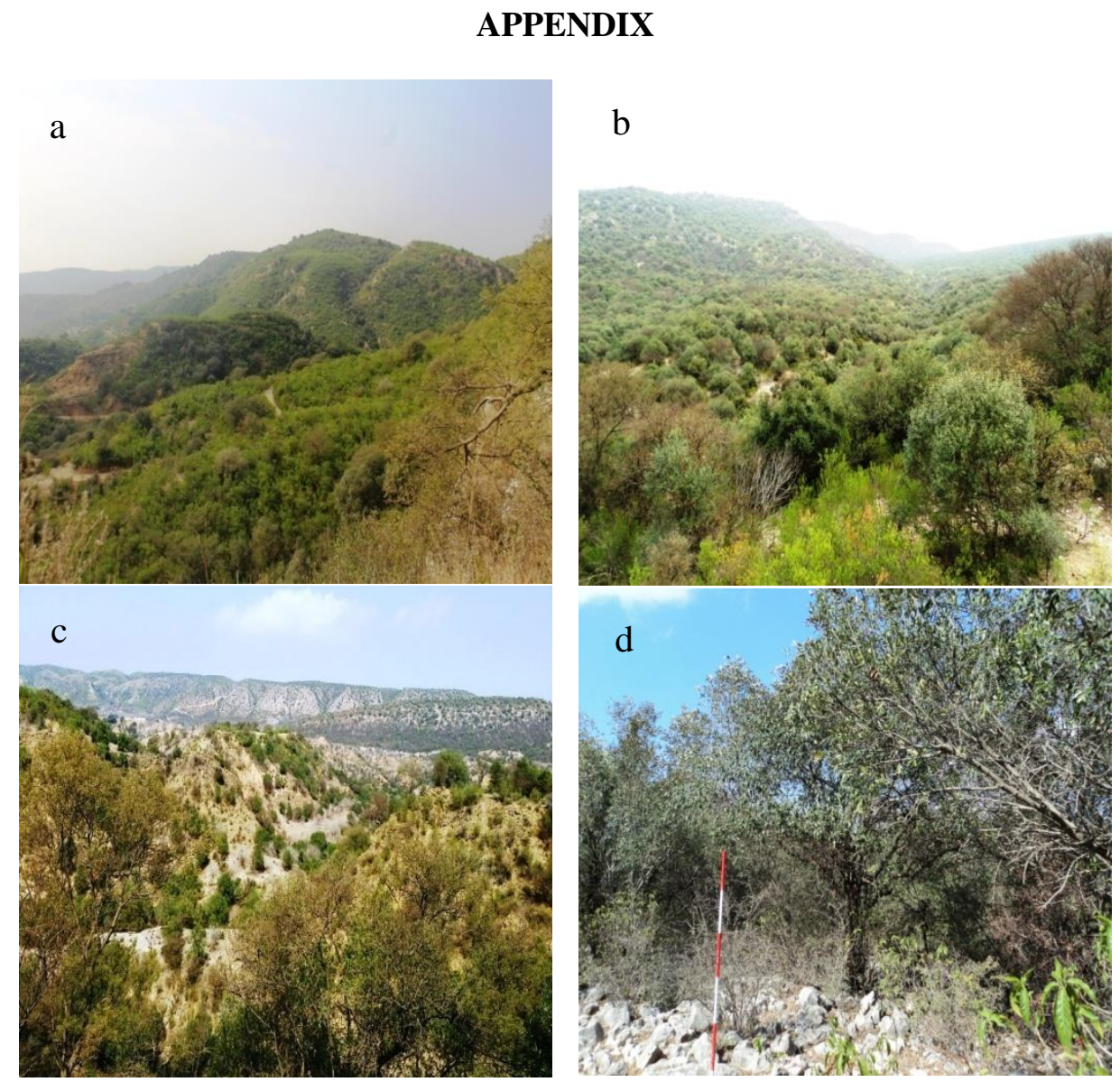

Figure A1. (a to c) Dense co-occurring bi-climax community of A. modesta and O. ferruginea with shrub cover in the HM forest, (d) Setting up of sampling plots for biomass estimation

Table A1. GPS coordinates and altitude of sampling plots

\begin{tabular}{c|c|c|c|c|c}
\hline Coordinates & Altitude $(\mathbf{m})$ & Coordinates & Altitude $(\mathbf{m})$ & Coordinates & Altitude (m) \\
\hline $32.54378 \mathrm{~N}, 72.24603 \mathrm{E}$ & 853 & $32.52299 \mathrm{~N}, 72.29811 \mathrm{E}$ & 806 & $32.54058 \mathrm{~N}, 72.28813 \mathrm{E}$ & 818 \\
$32.54378 \mathrm{~N}, 72.28457 \mathrm{E}$ & 895 & $32.52590 \mathrm{~N}, 72.30344 \mathrm{E}$ & 806 & $32.53712 \mathrm{~N}, 72.28403 \mathrm{E}$ & 801 \\
$32.54590 \mathrm{~N}, 72.29012 \mathrm{E}$ & 860 & $32.52658 \mathrm{~N}, 72.30799 \mathrm{E}$ & 823 & $32.53595 \mathrm{~N}, 72.28708 \mathrm{E}$ & 782 \\
$32.54565 \mathrm{~N}, 72.29782 \mathrm{E}$ & 889 & $32.52653 \mathrm{~N}, 72.31088 \mathrm{E}$ & 834 & $32.53663 \mathrm{~N}, 72.29047 \mathrm{E}$ & 788 \\
$32.54565 \mathrm{~N}, 72.30630 \mathrm{E}$ & 916 & $32.52851 \mathrm{~N}, 72.30931 \mathrm{E}$ & 835 & $32.53762 \mathrm{~N}, 72.29443 \mathrm{E}$ & 816 \\
$32.54650 \mathrm{~N}, 72.31582 \mathrm{E}$ & 964 & $32.53119 \mathrm{~N}, 72.30129 \mathrm{E}$ & 800 & $32.53912 \mathrm{~N}, 72.29766 \mathrm{E}$ & 815 \\
$32.54880 \mathrm{~N}, 72.31965 \mathrm{E}$ & 1011 & $32.53097 \mathrm{~N}, 72.29304 \mathrm{E}$ & 795 & $32.54180 \mathrm{~N}, 72.29531 \mathrm{E}$ & 822 \\
$32.55020 \mathrm{~N}, 72.32185 \mathrm{E}$ & 1017 & $32.53261 \mathrm{~N}, 72.28919 \mathrm{E}$ & 756 & $32.57238 \mathrm{~N}, 72.35765 \mathrm{E}$ & 865 \\
$32.54950 \mathrm{~N}, 72.32417 \mathrm{E}$ & 984 & $32.54402 \mathrm{~N}, 72.29347 \mathrm{E}$ & 835 & $32.56917 \mathrm{~N}, 72.35498 \mathrm{E}$ & 813 \\
$32.55020 \mathrm{~N}, 72.32721 \mathrm{E}$ & 952 & $32.54409 \mathrm{~N}, 72.30031 \mathrm{E}$ & 861 & $32.56480 \mathrm{~N}, 72.35040 \mathrm{E}$ & 833 \\
$32.55463 \mathrm{~N}, 72.32618 \mathrm{E}$ & 895 & $32.54099 \mathrm{~N}, 72.30845 \mathrm{E}$ & 826 & $32.55992 \mathrm{~N}, 72.35088 \mathrm{E}$ & 757 \\
$32.55580 \mathrm{~N}, 72.32853 \mathrm{E}$ & 975 & $32.53990 \mathrm{~N}, 72.31048 \mathrm{E}$ & 834 & $32.55402 \mathrm{~N}, 72.35090 \mathrm{E}$ & 620 \\
$32.53060 \mathrm{~N}, 72.28817 \mathrm{E}$ & 768 & $32.53807 \mathrm{~N}, 72.31328 \mathrm{E}$ & 842 & $32.55147 \mathrm{~N}, 72.34605 \mathrm{E}$ & 721 \\
$32.52850 \mathrm{~N}, 72.29045 \mathrm{E}$ & 779 & $32.53571 \mathrm{~N}, 72.31151 \mathrm{E}$ & 835 & $32.5500 \mathrm{~N}, 72.336530 \mathrm{E}$ & 885 \\
$32.52599 \mathrm{~N}, 72.29499 \mathrm{E}$ & 802 & $32.53370 \mathrm{~N}, 72.30923 \mathrm{E}$ & 823 & $32.55265 \mathrm{~N}, 72.33180 \mathrm{E}$ & 909 \\
$32.52153 \mathrm{~N}, 72.29754 \mathrm{E}$ & 788 & $32.54207 \mathrm{~N}, 72.29202 \mathrm{E}$ & 848 & & \\
\hline
\end{tabular}

